\title{
Stress and Its Association With Involvement in Online Classes: A Cross-sectional Study Among Undergraduate Students of a Medical College, South India
}

\author{
Rohith Motappa ( $\nabla$ drrohith88@gmail.com ) \\ Kasturba Medical College \\ Malavika Sachith \\ Yenepoya University \\ Pracheth $\mathbf{R}$ \\ Kasturba Medical College
}

\section{Research Article}

Keywords: Online classes, Perceived stress, COVID 19

Posted Date: January 7th, 2022

DOI: https://doi.org/10.21203/rs.3.rs-1102232/v1

License: (c) (1) This work is licensed under a Creative Commons Attribution 4.0 International License.

Read Full License 


\section{Abstract}

\section{Background}

With the implementation of lockdown and all students restricted to their houses, medical education has shifted towards the online mode. The objective of this study was to assess stress during the pandemic and the association between stress and involvement in online classes among students of a medical college in Mangalore, Karnataka, South India.

Methodology

A cross-sectional study was conducted among 324 undergraduate students at a medical college in Mangalore, Karnataka, South India. The extent of stress was assessed using a perceived stress scale (PSS), and a questionnaire was used to identify different stressors and to understand the participant's involvement in online classes. All methods were carried out in accordance with relevant guidelines and regulations.

Results

In this study, the mean perceived stress score was $21.66 \pm 4$. Moderate stress was observed in $262(85 \%)$ students. The main stressors noted were inability to focus (173 (56.4\%)) and fear of exams (153 $(49.8 \%))$. A significant association was noted between stress and involvement in online classes.

Conclusion

This study thereby highlights the need for more attention to the various stressors among students and for making online classes student friendly.

\section{Introduction}

Coronavirus disease 2019 (COVID-19) was first reported in Wuhan, Hubei Province, China. On January 27,

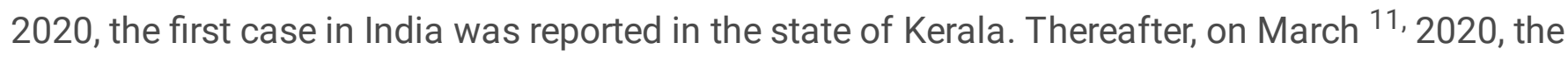
World Health Organisation declared it a pandemic (1).

COVID-19 is a novel organism that spread rapidly among people. Countries feared the doubling rate of the disease and the number of deaths due to it. Although people were being educated to practise preventive measures such as social distancing, wearing masks and sanitising hands, in countries such as India, the rates were still climbing. Hence, to break the chain of this infection, a nationwide complete lockdown was imposed in India on 24 March 2020 (2).

Lockdown is an emergency protocol that prevents people from leaving a given area. In the case of complete lockdown, only essential supplies such as grocery stores, pharmacies and banks continued to serve people. 
India is the country with the largest proportion of the population at a young age (3). Hence, when lockdown was imposed, they were the worst hit, as this was a generation that has never sat idle but was always on the go. Additionally, the last pandemic faced by India was the 2009 Swine flu (4), so this subject population is totally new to this disease and its preventive measures. As part of the lockdown, all educational institutions, including medical colleges, were shut down, and students were sent back home. Students are most affected by this, as they are losing out on their valuable school and college days. They are confined to the four walls of their households and are exposed to the outer world only virtually via the internet.

It was found that psychological symptoms such as depression and anxiety were elevated during the period of lockdown and isolation (5). Student suicide was noted during this period, with the first case occurring in Kerala being a 15-year-old committed suicide (6).

In studies conducted during the pandemic, it was found that stress, anxiety and depression due to COVID19 were prevalent among the general population (7). Among students, medical students were generally found to have higher stress than nonmedical students (8). With the implementation of the lockdown, all the students were sent home, and online teaching was the only way to continue education.

Online education is an electronic learning tool that relies on the internet for teacher/student interaction and the distribution of class material. In this way, a student can turn anywhere with internet access and electricity into a virtual classroom. Although this method was introduced as an add on to traditional teaching and learning experience, with COVID-19 still prevalent throughout the world, it has become the new normal for generation $Z$.

Medical students are the upcoming doctors. Being at home and with an indefinite closure of colleges, there is a prevailing fear of the future among students. For the past 7-8 months, they were attending online classes. This has affected medical education with no more practical classes. This study aimed to assess stress during the pandemic and the association between stress and involvement in online classes among students of a medical college in Mangalore, Karnataka, South India.

\section{Materials And Methods}

Institution Ethics Committee approval (YEC/2) from Yenepoya Ethics Committee -2, Yenepoya University and permission from the institutional head were obtained before conducting the study. This is a crosssectional study conducted among medical students studying Bachelor of Medicine and Bachelor of Surgery (MBBS) at Yenepoya Medical College situated in Mangalore taluk, Dakshina Kannada district, Karnataka, South India. The study was conducted from November to December 2020. Complete enumeration was used to enrol participants in this study, including studying participants from the first to final year, and the total sample size was 600 . Approximately six attempts were made to reach out the participants through their online classes and WhatsApp groups, but we did not receive the desired response from the students. Thereby, the final sample size was accounted to 324 . 
A predesigned, validated, semi structured questionnaire was used to capture information. Demographic variables such as age, sex, religion, year of study and current place of stay were included. The Perceived Stress Scale (PSS), a classic instrument to assess stress, was also incorporated into the questionnaire (9). The questions here ask about the feelings and thoughts of the participants during the last month. It is a 10-item questionnaire with responses in the form of how often participants did experience certain situations from 0 -never to 4 -very often. Scores ranging from 0 to 13 were considered low stress. Scores ranging from 14 to 26 were considered moderate stress. Scores ranging from 27 to 40 were considered high perceived stress. Questions pertaining to the participants' involvement in online classes conducted by the college were also included. The Google Form also included a participant information sheet and informed consent. All participants were voluntary, and it was described that the identity and the information given would remain strictly confidential. The Google Form responses were downloaded in a coma separated value (CSV) format, and the data captured were then cleaned. Data collected were analysed using SPSS Version 23. Descriptive statistics such as the mean, frequency and proportion were applied. The chi-square test was used to study the association between stress and involvement in online classes.

All methods were carried out in accordance with relevant guidelines and regulations.

\section{Results}

A total of 324 students responded to the survey. The mean age of the students was $21 \pm 2$ years. The characteristics of the students are depicted in Table 1. The mean perceived stress score was $21.66 \pm 4$. Out of 307 students, moderate stress was observed in 262 (85\%) students (Figure 1). Among the various stressors identified, inability to focus and fear of exams were the most common stressors (173 (56.4\%) and $153(49.8 \%)$, respectively) (Table 2), and other stressors were record completions, phone addiction, etc.

\section{Table 1: Demographic characteristics of the participants $(n=307)$}




\begin{tabular}{|lll|}
\hline Variable & Frequency $(\mathbf{n})$ & Percentage (\%) \\
\hline Gender & & \\
\hline Male & 122 & 39.7 \\
\hline Female & 185 & 60.3 \\
\hline Religion & & \\
\hline Hindu & 113 & 36.8 \\
\hline Muslim & 166 & 54.1 \\
\hline Christian & 28 & 9.1 \\
\hline Year of study & & \\
\hline $1^{\text {st }}$ year & 128 & 41.7 \\
\hline $2^{\text {nd }}$ year & 117 & 38.1 \\
\hline $3^{\text {rd }}$ year & 34 & 11.1 \\
\hline $4^{\text {th }}$ year & 28 & 9.1 \\
\hline Place of residence & \\
\hline Hostel & 253 & 82.4 \\
\hline Day scholar & 54 & 17.6 \\
\hline
\end{tabular}

Table 2: Different stressors of students $(n=307)$

\begin{tabular}{|lll|}
\hline Variable* & Frequency (n) & Percentage (\%) \\
\hline 1. Prolonged stay at home & 98 & 31.9 \\
\hline 2. Inability to attend classes & 70 & 22.8 \\
\hline 3. Difficulty in grasping & 135 & 44 \\
\hline 4. Inability to focus in studies & 173 & 56.4 \\
\hline 5. Fear of exams & 153 & 49.8 \\
\hline 6. Fear of COVID 19 infection & 63 & 20.5 \\
\hline 7. In adequate information of COVID 19 & 17 & 5.5 \\
\hline 8. Financial situation of family & 62 & 20.2 \\
\hline 9. College fees & 83 & 27 \\
\hline
\end{tabular}


*Multiple response questions

Table 3: Association of perceived stress categories with involvement in online classes $(n=307)$

\begin{tabular}{|c|c|c|c|c|c|}
\hline & Mild stress & Moderate stress & High stress & Total & p value \\
\hline \multicolumn{6}{|c|}{ Do you remember the contents of online classes appropriately? } \\
\hline Yes & 8 & 67 & 3 & 78 & \multirow[t]{2}{*}{0.01} \\
\hline No & 4 & 195 & 30 & 229 & \\
\hline \multicolumn{6}{|c|}{ How many hours of online classes do you attend daily? } \\
\hline Less than 3 hours & 8 & 159 & 12 & 179 & \multirow[t]{2}{*}{0.02} \\
\hline More than 3 hours & 4 & 103 & 21 & 128 & \\
\hline \multicolumn{6}{|c|}{ Are you finding it difficult to concentrate in online classes? } \\
\hline Yes & 6 & 198 & 30 & 234 & \multirow[t]{2}{*}{0.01} \\
\hline No & 6 & 64 & 3 & 73 & \\
\hline \multicolumn{6}{|c|}{ Are you facing difficulty in understanding online classes? } \\
\hline Yes & 4 & 164 & 26 & 194 & \multirow[t]{2}{*}{0.08} \\
\hline No & 8 & 98 & 7 & 113 & \\
\hline \multicolumn{6}{|c|}{ Are you facing technological difficulty? } \\
\hline Yes & 4 & 129 & 20 & 153 & \multirow[t]{2}{*}{0.5} \\
\hline No & 8 & 133 & 13 & 154 & \\
\hline \multicolumn{6}{|c|}{ Are the hours of studying increased or decreased? } \\
\hline Increased & 5 & 73 & 7 & 85 & \multirow[t]{3}{*}{0.6} \\
\hline Same & 2 & 42 & 8 & 52 & \\
\hline Decreased & 5 & 147 & 18 & 170 & \\
\hline
\end{tabular}

In assessing the preference for the mode of teaching among medical students pre- and post-pandemic, it was observed that the offline mode of teaching was preferred during both periods $(226(73.6 \%)$ and 170 (55.4\%), respectively).

The association between perceived stress score and online classes is depicted in Table 3. There was a statistically significant association between perceived stress score and remembering content of online classes $(p<0.05)$, between perceived stress score and hours of classes attended $(p<0.05)$, and between perceived stress score and difficulty in concentrating online classes $(p<0.05)$. 


\section{Discussion}

This study explored stress among 307 medical undergraduates of a medical college in South India and its association with involvement in online classes.

Although there are many studies assessing the stress level among medical students, this is one of the few studies conducted in South India aimed at identifying different stressors and their association with involvement in online classes during this COVID pandemic.

In this study, the mean perceived stress score was $21.66 \pm 4$, with moderate stress in 262 (85\%) students. These findings were contrary to a study conducted by Joseph et al in which the mean stress score was $13.3 \pm 4.2(10)$. This could be attributed to the fact that our study was conducted during a period of pandemic with the whole world in immense stress.

The newer stressors due to online learning found in our study were inability to focus on studies, fear of exams, prolonged stay at home, etc., while previous studies suggest that potential stressors for medical students are academic workload and poor time management (11)(12). These findings were similar to those of a study conducted by Abdulghani et al. (13). COVID-related stressors were also noted, such as fear of infection and inadequate information on the disease, and these were consistent with a study conducted by Luberto et al. (14).

Out of the 307 students who participated, 170 (55\%) students experienced a decrease in overall time spent in studies after the implementation of online classes, which was consistent with the findings of previous studies (15).

The association between perceived stress score and remembering contents of online classes was found to be statistically significant in our study $(p<0.05)$. Among the 78 students who did not remember the contents of online classes, moderate stress was noted among 67 (85\%) students (16).

In the present study, it was found that before the COVID pandemic and lockdown, only 55 (17.9\%) students preferred the blended mode of classes with both online and offline modes. After the implementation of the lockdown, the number increased to 109 (35.5\%). This is similar to a study conducted by Suryawanshi DM et al. (17).

The study results highlight the fact that issues related to online teaching have become a new stressor for already stressed medical students. As online medical education is a new and evolving concept, the education system should make specific modules to help students. Additionally, students should be properly oriented for these classes, and individual-level monitoring must be done not just by teachers but also by parents. Tailor-made coping strategies must be developed for students to ease their stress. In the long run, colleges should modify the learning experience for each student with access to current technologies and the availability of resources for effective learning. 
The strength of this study was that perceived stress scale, a standardised stress scale was used in this study to access the stress level among the medical students and open-ended questions were asked to identify the different stressors. This study is reported according to the STROBE statement for reporting cross-sectional studies.

The study had several limitations. The study cannot be completely generalised, as it was conducted in a single private medical college. Here, most of the students were financially secure; hence, the study did not gather information about the needs of students with disabilities during the transition to online courses. As the study was based on a self-administered questionnaire, the chance of reporting bias could not be eliminated. Since the PSS questions are based on the experience of the students in the previous month, there is also a chance for memory or recall bias.

The addition of beneficial coping tactics utilised by students during testing times, such as the COVID-19 epidemic, is advocated for further research. In the "new normal" arena, research should also be directed toward teaching, learning, and evaluation strategies that can maximise learning results while minimising anxiety and negative psychological effects among students.

\section{Conclusion}

Moderate perceived stress was observed in approximately $85.3 \%$ of students. Inability to focus on studies, fear of exams, and difficulty grasping are the key stressors. Due to this long-term lockdown due to the COVID-19 pandemic, the online mode of learning was the only way to continue medical education, which may cause further worsening of the psychological and learning behaviours of these students. Despite these difficulties, students' faith in the efficiency of online medical education has grown as a result of their experiences during the first few weeks of the pandemic. While pandemics have historically posed difficulties, recognising these difficulties is the first step toward turning them into possibilities.

\section{Declarations}

\section{Acknowledgements}

The authors express their gratitude to all of the undergraduate students for their support and valuable time given by them for filling out the questionnaires.

\section{Funding - None}

Conflicts of interest/Competing interests - None

Availability of data and material - Transparent

Ethics approval - Obtained 
Consent to participate - Informed consent was obtained from all individual participants included in the study.

Consent for publication (include appropriate statements)- Additional informed consent was obtained from all individual participants for whom identifying information was included in this article.

\section{References}

1. Timeline of WHO's response to COVID-19. WHO.

https://www.who.int/emergencies/diseases/novel-coronavirus-2019/interactive-timeline/Accessed May 102021.

2. Hebbar Nistula. PM Modi announces 21-day lockdown as COVID-19 toll touches 12 . The Hindu [Internet]. 2020/March; https://www.thehindu.com/news/national/pm-announces-21-day-lockdown-ascovid-19-toll-touches-10/article31156691.ece/Accessed May 102021.

3. Age Structure And Marital Status. Office of the Registrar General \& Census Commissioner, India. https://censusindia.gov.in/census_and_you/age_structure_and_marital_status.aspx/Accessed May 10 2021.

4. Choudhry A, Singh S, Khare S, Rai A, Rawat DS, Aggarwal RK, et al. Emergence of pandemic 2009 influenza A H1N1, India. Indian J Med Res [Internet]. 2012 Apr [cited 2021 May 10];135(4):534-7. Available from:/pmc/articles/PMC3385239/

5. Brooks SK, Webster RK, Smith LE, Woodland L, Wessely S, Greenberg N, et al. The psychological impact of quarantine and how to reduce it: rapid review of the evidence [Internet]. Vol. 395, The Lancet. Lancet Publishing Group; 2020 [cited 2021 May 10]. p. 912-20. Available from: https://doi.org/10.1016/

6. Lathabhavan R, Griffiths M. First case of student suicide in India due to the COVID-19 education crisis: A brief report and preventive measures [Internet]. Vol. 53, Asian Journal of Psychiatry. Elsevier B.V.; 2020 [cited 2021 May 10]. p. 102202. Available from:/pmc/articles/PMC7297156/

7. Salari N, Hosseinian-Far A, Jalali R, Vaisi-Raygani A, Rasoulpoor S, Mohammadi M, et al. Prevalence of stress, anxiety, depression among the general population during the COVID-19 pandemic: A systematic review and meta-analysis [Internet]. Vol. 16, Globalisation and Health. BioMed Central; 2020 [cited 2021 May 10]. p. 1-11. Available from: https://doi.org/10.1186/s12992-020-00589-w

8. Aamir IS. Stress Level Comparison of Medical and Nonmedical Students: A Cross Sectional Study done at Various Professional Colleges in Karachi, Pakistan. Acta Psychopathol [Internet]. 2017 Mar 31 [cited 2021 May 10];03(02). Available from: http://www.imedpub.com

9. State of New Hampshire Employee Assistance Program. Perceived Stress Scale Score Cut Off. State New Hampsh Empl Assist Progr. 1983;2. 
10. Joseph N, Joseph N, Panicker V, Nelliyanil M, Jindal A, Viveki R. Assessment and determinants of emotional intelligence and perceived stress among students of a medical college in south India. Indian $\mathrm{J}$ Public Health. 2015;59(4):310.

11. Chowdhury R, Mukherjee A, Mitra K, Naskar S, Karmakar PR, Lahiri SK. Perceived psychological stress among undergraduate medical students: Role of academic factors. Indian J Public Health. 2017;61(1):55-7.

12. Hill MR, Goicochea S, Merlo LJ. In their own words: stressors facing medical students in the millennial generation. Med Educ Online [Internet]. 2018;23(1). Available from: https://doi.org/10.1080/10872981.2018.1530558

13. Abdulghani HM, Sattar K, Ahmad T, Akram A. Association of covid-19 pandemic with undergraduate medical students' perceived stress and coping [response to letter]. Psychol Res Behav Manag. 2020;13:1101-2.

14. Luberto CM, Goodman JH, Halvorson B, Wang A, Haramati A. Stress and Coping Among Health Professions Students During COVID-19: A Perspective on the Benefits of Mindfulness. Glob Adv Heal Med. 2020;9:216495612097782.

15. Kapasia N, Paul P, Roy A, Saha J, Zaveri A, Mallick R, et al. Impact of lockdown on learning status of undergraduate and postgraduate students during COVID-19 pandemic in West Bengal, India. Child Youth Serv Rev [Internet]. 2020;116(June):105194. Available from: https://doi.org/10.1016/j.childyouth.2020.105194

16. Meo SA, Abukhalaf AA, Alomar AA, Sattar K, Klonoff DC. COVID-19 Pandemic: Impact of Quarantine on Medical Students' Mental Wellbeing and Learning Behaviors. Pak J Med Sci [Internet]. 2020 [cited 2020 Oct 7];36:43-8. Available from: https://doi.org/10.12669/pjms.36.COVID19-S4.2809

17. Suryawanshi DM, Venugopal R. Preferences, perceptions and barriers to E-learning among medical students during COVID-19 pandemic lockdown in India. Int J Community Med Public Heal. 2020;7(10):4100.

\section{Figures}




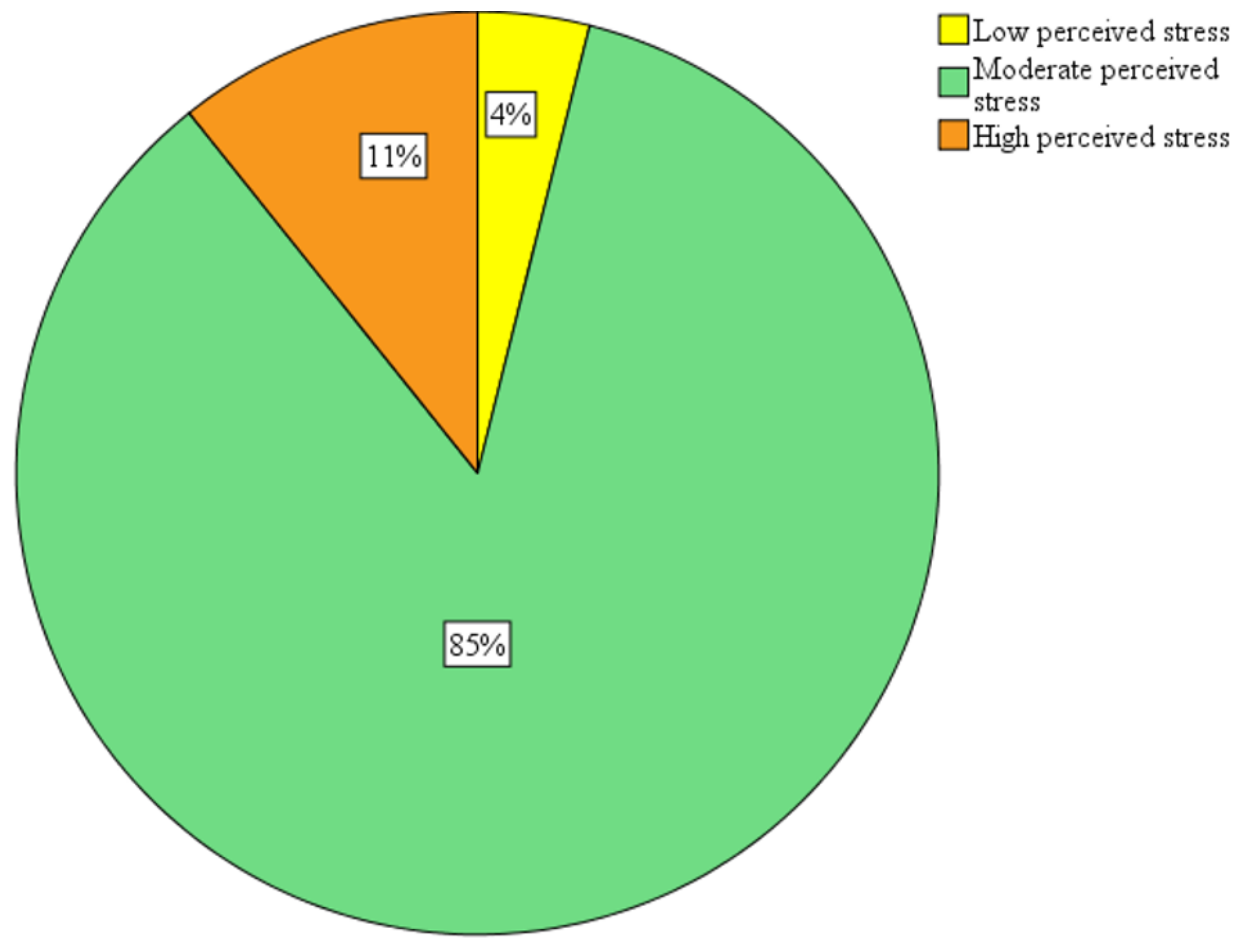

Figure 1

Stress level among medical students 